\title{
BMJ Open International psychometric validation of the Living with Chronic Illness Scale in Spanish-speaking patients with chronic obstructive pulmonary disease
} \begin{tabular}{l}
\hline Silvia Corchon, ${ }^{1}$ Carmen Rodriguez-Blazquez, ${ }^{2}$ Gloria Carvajal-Carrascal, ${ }^{3}$ \\
Alejandra Fuentes-Ramirez, ${ }^{3}$ Manuel Ignacio Ruiz de Ocenda, ${ }^{4}$ Neus Caparros, ${ }^{5}$ \\
Eva Timonet-Andreu, ${ }^{6}$ Maria Victoria Navarta-Sanchez, ${ }^{7}$ Leire Ambrosio
\end{tabular}

To cite: Corchon S, RodriguezBlazquez C, CarvajalCarrascal G, et al. International psychometric validation of the Living with Chronic IIIness Scale in Spanish-speaking patients with chronic obstructive pulmonary disease. BMJ Open 2021;11:e039973. doi:10.1136/ bmjopen-2020-039973

- Prepublication history for this paper is available online. To view these files, please visit the journal online (http://dx.doi. org/10.1136/bmjopen-2020039973).

Received 01 May 2020 Revised 30 July 2020 Accepted 07 0ctober 2020

\section{Check for updates}

(c) Author(s) (or their employer(s)) 2021. Re-use permitted under CC BY-NC. No commercial re-use. See rights and permissions. Published by BMJ.

For numbered affiliations see end of article.

\section{Correspondence to}

Dr Leire Ambrosio;

L.Ambrosio-Gutierrez@soton. ac.uk

\section{ABSTRACT}

Objectives To validate the Living with Chronic IIIness (LW$\mathrm{Cl}$ Scale in patients with chronic obstructive pulmonary disease (COPD).

Design Observational, cross-sectional validation study with retest. Acceptability, reliability, precision and construct validity were tested.

Setting The study took place in primary and secondary specialised units of public and private hospitals of Spain and Colombia.

Participants The study included 612 patients with COPD assessed from May 2018 to May 2019. A consecutive cases sampling was done. Inclusion criteria included: $(A)$ patients with a diagnosis of COPD; $(B)$ native Spanish speaking; (C) able to read and understand questionnaires; and (D) able to provide informed consent. Exclusion criteria included: (A) cognitive deterioration and (B) pharmacological effect or disorder that could disrupt the assessment.

Results The LW-Cl-COPD presented satisfactory data quality, with no missing data or floor/ceiling effects, showing high internal consistency for all the domains (Cronbach's alpha for the total score 0.92). Test-retest reliability was satisfactory (intraclass correlation coefficient=0.92). The LW-CI-COPD correlated 0.52-0.64 with quality of life and social support measures. The scale demonstrated satisfactory known-groups validity, yielding significantly different scores in patients grouped according to COPD severity levels.

Conclusions This has been the first validation study of the LW-CI-COPD. It is a feasible, reliable, valid and precise self-reported scale to measure living with COPD in the Spanish-speaking population. Therefore, it could be recommended for research and clinical practice to measure this concept and evaluate the impact of centred-care interdisciplinary interventions based on the patients' perspective, focused on providing holistic and comprehensive care to patients with COPD.

\section{INTRODUCTION}

In the 20th century, the important changes in demographics, lifestyles, social and environmental factors have led to a significant increase in chronic conditions in Western
Strengths and limitations of this study

- The sample size $(n=612)$ is a strength of this study considering the difficulties in the recruitment of this population due to the symptomatology and disease exacerbations.

- The sample represented a heterogeneous population showing the different levels of illness severity.

- The inclusion of Spanish-speaking population from different cities and two countries supported the consistency of the results and the possibility of generalisation at least for these cultural and linguistic settings.

- The test was completed in the office and the retest in patients' home, a circumstance that could have added a spurious variability and limitation in results.

- The inclusion of two countries could be a limitation because of the cultural differences.

countries, being the leading cause of disability, morbidity, mortality and costs. ${ }^{1}$ Therefore, healthcare, social systems and policies need to be focused on chronic conditions. ${ }^{2}$

The chronic obstructive pulmonary disease (COPD) is one of the most prevalent and prototypical chronic conditions. ${ }^{3}$ This disease is among the main causes of hospitalisations, visits to emergency departments ${ }^{45}$ and mortality worldwide, accounting for more than 3.2 million deaths. ${ }^{6}$ In Spain, COPD is the third cause of death, after cardiovascular diseases and cancer, ${ }^{7}$ and in Colombia, it is among the three principal causes of natural death. ${ }^{8}$ This is a fact that produces a huge economic and social burden. Moreover, the projection for the next years is that the number of people living with COPD will increase due to the exposure to risk factors and the changing population demographics. ${ }^{45}$ COPD is a complex chronic respiratory condition, usually caused by exposure 
to toxic gases or particles, characterised by an airflow obstruction that produces respiratory symptoms. ${ }^{35}$ This chronic illness progressively worsens over time leading patients to experience an intensification of symptoms, such as dyspnoea and cough, and limitations to the performance of activities of daily living. ${ }^{9}$ This exacerbation could affect patients' daily living, quality of life and satisfaction with life. ${ }^{910}$

The desired outcomes for patients living with COPD are related to improve functional status, social life and quality of life, as well as to decrease distressing symptoms and healthcare demands. To achieve those objectives, it is necessary to understand how a person lives with this disease to provide individualised and person-centred care. $^{11}$

Living with COPD is a complex, dynamic, cyclic and multidimensional process that embraces internal processes such as acceptance and coping with the situation, self-management of the symptoms, integration of the disease in the daily living and adjustment to the new life generated by the disease. ${ }^{12}$ Therefore, healthcare professionals, and more specifically nurses, need to understand from the patients' perspective how the daily living with COPD is. This understanding will generate the required knowledge to provide holistic and individualised care to patients. ${ }^{10}$ Nurses are the health professionals who could lead multidisciplinary teams to address the physical aspects and the psychological and social needs of patients living with COPD.

To achieve an understanding of the process of living with COPD, it is necessary to use adequate instruments that assess the concept holistically and from the patients' perception. To date, there are several tools that measure aspects related to living with COPD, but those address this issue in a fragmented way without considering the holistic perspective of care. For instance, the International Physical Activity Questionnaire and the modified Medical Research Council (mMRC) dyspnoea grade both exclusively focused on the symptoms and physical aspects of patients. ${ }^{1314}$ In addition to these, there are some generic instruments that measure quality of life, such as the WHO Quality of Life Instrument. ${ }^{15}$ Besides, other specific instruments measure health-related quality of life in patients with COPD and other pulmonary diseases, such as the St George's Respiratory Questionnaire (SGRQ) ${ }^{16}$ and the COPD Assessment Test (CAT).$^{17}$ The SGRQ is a widely used tool that evaluates the disease symptomatology, its impact on physical activity and some psychological aspects. ${ }^{18-20}$ The CAT assesses and monitors the impact of COPD on patients' health status. ${ }^{17}$ Nevertheless, those instruments do not address the concept of living with a chronic condition.

In this way, there is only one available scale in research and clinical practice to evaluate how patients live with a chronic illness, the Living with Chronic Illness (LW-CI) Scale. The LW-CI Scale has been previously published for Spanish-speaking population in a pilot study carried out in patients living with different chronic conditions such as Parkinson's disease, diabetes mellitus type 2, osteoarthritis or chronic heart failure showing excellent psychometric results. ${ }^{1121}$ This self-reported scale addresses the construct from a comprehensive approach, focusing on the person and not on the disease. ${ }^{11}$ It allows identifying the factors that help a person to live positively with the illness. This information is essential to conduct research in this area and to design individualised care interventions that address the actual needs of each patient.

The objective of the study presented here is to validate the LW-CI Scale in a sample of patients with COPD, living in Spain and Colombia.

\section{METHODS \\ Design}

An observational, international and cross-sectional study was carried out with retest evaluation.

This study is part of a macro research project with the general aim to achieve a unique Spanish-speaking selfreported scale to evaluate the process of living with one or more than one chronic disease, such as diabetes mellitus type 2, rheumatoid and osteoarthritis, chronic heart failure, high blood pressure and Parkinson's disease. This study was focused on the validation of the scale with people living with COPD in a Spanish-speaking population, which is part of a series of validation studies carried out in different chronic diseases and countries. ${ }^{11} 21$

We used the Strengthening the Reporting of Observational Studies in Epidemiology cross-sectional checklist when writing our report. ${ }^{22}$

\section{Patients}

The sample for this study was composed of consecutive COPD outpatients from primary and secondary specialised units of different public and private hospitals of Spain and Colombia. Patients were included in this study according to the following inclusion criteria: (A) patients with a diagnosis of COPD by a primary physician or pneumologist; (B) native Spanish-speaking patients; (C) patients able to read and understand properly questionnaires; and (D) people able to provide informed consent. Exclusion criteria were: (A) cognitive deterioration or mental disorders; (B) pharmacological effect or acute disorder that could potentially disrupt the assessment; and $(\mathrm{C})$ patients who do not meet established inclusion criteria.

\section{Sampling and sample size}

A consecutive cases sampling was carried out. ${ }^{23} 24$ The sample size was calculated according to international criteria $^{25}$ following the rule of 5-10 participants per item of the scale. In this sense, considering that the LW-CI Scale for patients with COPD (LW-CI-COPD) is a 26-item scale, a minimum sample size between 130 and 260 people living with COPD was estimated. Moreover, a statistical calculation of the sample size was also conducted. The sample size was based on estimating correlation to a suitable 
degree of precision. Therefore, assuming a correlation of 0 (a worst-case scenario in statistical terms), a sample size of 267 people living with COPD ensured a $95 \%$ CI no wider than \pm 0.12 .

\section{Patient and public involvement}

For this phase of the instrument testing, patients were not directly involved because they were highly involved in the previous pilot phase. ${ }^{21}$ As shown in the previous study of this validation study, patients and the public were directly involved in the design and pilot phase through qualitative and quantitative methodologies. ${ }^{21}$ For the qualitative data, in-depth interviews and focus groups were carried out with 15 people living with COPD and other chronic conditions. For the quantitative data, an ad hoc questionnaire of the LW-CI Scale was developed to analyse content validity. ${ }^{21}$ For this validation study, patients were just involved in the study to answer the LW-CI-COPD, because the main objective of this study is to identify the psychometric attributes of the scale using a classic test theory approach. Nevertheless, patients living with COPD will be contacted again in the following phases of the study to develop the implementation and dissemination strategy of the scale in clinical practice and community groups.

\section{Assessments}

A questionnaire was used to collect the personal data of the patient living with COPD related to gender, age, marital status, educational level and employment situation, and data related to the COPD: age at diagnosis, disease duration, and type and duration of treatment for COPD. As in other validation studies carried out in Spain and South America, ${ }^{11}$ in addition to sociodemographic, disease-related data, and the LW-CI-COPD, the following self-reported scales were used:

- The Duke-UNC Functional Social Support Questionnaire (DUFSS) ${ }^{2627}$ was used to evaluate social support of the patients from their perspective. It is an 11-item tool that evaluates different dimensions of social support as confidant, affective and instrumental support. The score for each item varies from 1 (much less than I would like) to 5 (as much as I would like).

- The WHO Quality of Life Instrument-Brief (WHOQOL-BREF $)^{15}$ was used to measure the quality of life of the patients. The WHOQOL-BREF comprised 24 items that evaluate physical health, psychological health, social relationships and environment. Item response options range from 1 (very dissatisfied) to 5 (very satisfied/very good quality of life).

- The modified version of the Satisfaction with Life Scale (SLS-6) ${ }^{28}$ evaluates the overall satisfaction with life (item 1) and in regard to other five areas: physical, psychological well-being, social relations, leisure and financial situation. Each item scores from 0 (unsatisfied) to 10 (totally satisfied).

- The Patient-Based Global Impression of Severity Scale (PGIS) ${ }^{29}$ was used to evaluate the patient global impression of severity of the COPD. It is a 6-point Likert scale ranging from 0 (not ill at all) to 5 (extremely ill) according to the patient's own impression.

- The mMRC Dyspnoea Scale classifies the severity of dyspnoea in respiratory diseases, particularly COPD. It ranges from 0 (dyspnoea only with strenuous exercise) to 4 (too dyspnoeic to leave the house or breathless when dressing).

For this study, the Spanish validated version of the scales was used.

\section{Data collection}

Data collection was carried out from November 2018 to May 2019 in Colombia and from May 2018 to May 2019 in Spain. In order to ensure homogeneity and reduce possible errors during data collection, all centres from Spain and Colombia followed a detailed protocol. The principal researcher of the study ensured that all researchers involved in this process understood the established steps before starting data collection. The main steps detailed in the protocol were the following: potential participants were approached through the health professionals (nurse or physician); an invitation letter and the participant information sheet were provided to explain this study; patients were cited to complete the questionnaires when they accorded with their health professional or researcher.

Data collection related to test-retest was also protocolised to minimise potential random errors. Patients were asked to answer a second time to the LW-CI-COPD at home. The LW-CI-COPD was in a stamped envelope with research postal direction in order to complete the questionnaire and send it in an easy and cost-free way. According to experts in this field, ${ }^{26}$ a minimum sample of 50 subjects and a time span of $7-10$ days for the retest was planned.

\section{Data analysis}

The main outcome data were ordinal or did not fit a normal distribution, thus non-parametric statistics were used. Descriptive statistics were calculated to characterise the sample. For the LW-CI-COPD, the following psychometric attributes were analysed: data quality and acceptability, reliability, precision and validity.

For data quality and acceptability, missing data (acceptable if $<5 \%$ ), ${ }^{30}$ floor and ceiling effects (adequate if $<15 \%$ for both) ${ }^{30}$ and skewness of the distribution (value within -1 to +1$)^{31}$ were computed.

For internal consistency, Cronbach's alpha coefficient (criterion value: alpha $\geq 0.70),{ }^{32}$ item-total correlation corrected for overlap (criterion: $r \geq 0.30),{ }^{30}$ interitem homogeneity (criterion: $r \geq 0.20$ and $\leq 0.75)^{30}$ and item homogeneity index (criterion value $>0.30$ ) were calculated. For reproducibility, the following test-retest parameters were determined: weighted kappa with quadratic weights for items (criterion: $>0.40$ moderate) ${ }^{33}$ and intraclass correlation coefficient (ICC; one way, random effect; criterion $\geq 0.70)^{34}$ for domains and total score. 
Precision was determined with the standard error of measurement (SEM) ${ }^{32}$ with the formula:

$$
S E M=S D_{\text {pooled }} * \sqrt{\left(1-r_{x x}\right)}
$$

where $\mathrm{SD}_{\text {pooled }}=S D_{\text {pooled }}=\sqrt{\left(S D_{1}^{2}+S D_{2}^{2}\right) / 2}$

with $r_{x x}$ being the test-retest reliability (ICC). A SEM value $<0.5 \mathrm{SD}$ was used as a criterion of acceptable precision. $^{35}$

Finally, construct validity was tested. For hypotheses testing, LW-CI-COPD convergent and known-groups validity was determined. ${ }^{36}$ Based on previous studies, strong $(r>0.50)$ or moderate $(r \geq 0.35-0.50)$ Spearman's rank correlation coefficients ${ }^{37} 38$ between LW-CI-COPD and the rest of applied rating scales (DUFSS, SLS-6, WHOQOL-BREF) were hypothesised. Differences in LW-CI-COPD scores in the sample grouped by variables of interest (gender, PGIS and mMRC severity levels) were tested using Mann-Whitney and Kruskal-Wallis tests for comparisons. Regarding internal validity, it was ascertained with the intercorrelations of the domains that compose the scale (standard, $r=0.30-0.70$ ). ${ }^{31}$

All analyses were performed using SPSS V.22.0 (IBM).

\section{RESULTS}

A total of 612 patients living with COPD were included in this study. The sample was composed of $44.3 \%$ women, and the mean age was $70.62 \pm 11.96 .49 .5 \%$ of the sample were married, $60.2 \%$ had primary educational level and $35 \%$ were retired. According to the historical data of COPD, $81.1 \%$ of the sample had pharmacological treatment for COPD, with a duration of $6.91 \pm 6$ years. The mean of COPD duration was $8.29 \pm 6.5$ years. The distribution according to mMRC was the following: $4.9 \%$ in level $0 ; 37.8 \%$ in level 1; $29.6 \%$ in level 2; 19.3 in level 3; and $8.3 \%$ in level $4.81 .1 \%$ was taken specific treatment for the COPD. See table 1 for more details.

Results related to data quality and acceptability are shown in table 2 . There were no missing values and $100 \%$ of the data were computable. Floor and ceiling effects for the LW-CI-COPD total score were $0.2 \%$ and $0.8 \%$, respectively. None of the domains presented floor effect and only domain 1-acceptance, domain 4-integration and domain 5-adjustment showed a ceiling effect. The domains and total score of the LW-CI-COPD did not show skewness.

Concerning internal consistency, Cronbach's alpha for the LW-CI-COPD total was 0.92 and for the domains ranged from 0.77 (domain 3-self-management) to 0.90 (domain 1-acceptance). Item homogeneity by domains ranged from 0.41 (domain 2-coping) to 0.68 (domain 1 -acceptance). As shown in table 2, all corrected itemtotal correlations were higher than 0.30 .

Regarding the reproducibility (test-retest) of the LW-CI-COPD, it was tested in 118 patients living with COPD. The ICC for the total scale score was 0.92 and for all the domains was $\geq 0.86$ (see table 2). For individual
Table 1 Sociodemographic characteristics of the patients $(n=612)$ and historical data of COPD

\begin{tabular}{|c|c|c|}
\hline $\begin{array}{l}\text { Demographic } \\
\text { variables }\end{array}$ & Response options & $\begin{array}{l}\text { Total patients } \\
\text { living with } \\
\text { COPD n (\%) }\end{array}$ \\
\hline \multirow[t]{2}{*}{ Gender } & Male & 341 (55.7) \\
\hline & Female & 271 (44.3) \\
\hline \multirow[t]{4}{*}{ Marital status } & Married & $303(49.5)$ \\
\hline & Single & $80(13.1)$ \\
\hline & Widower & $178(29.1)$ \\
\hline & Others & $51(8.3)$ \\
\hline \multirow{4}{*}{$\begin{array}{l}\text { Employment } \\
\text { situation }\end{array}$} & Active working & $51(8.3)$ \\
\hline & Housekeeper & $211(34.5)$ \\
\hline & Retired & $214(35.0)$ \\
\hline & Others & $136(22.2)$ \\
\hline \multirow{4}{*}{ Educational level } & Primary studies & $367(60.2)$ \\
\hline & Secondary studies & $165(27.0)$ \\
\hline & University studies & $66(10.8)$ \\
\hline & Others & $12(2.0)$ \\
\hline \multirow{2}{*}{$\begin{array}{l}\text { Treatment for } \\
\text { COPD }\end{array}$} & Yes & 314 (81.1) \\
\hline & No & 73 (18.9) \\
\hline \multirow[t]{6}{*}{ mMRC } & $\begin{array}{l}0 \text { (Dyspnoea only with } \\
\text { strenuous exercise) }\end{array}$ & $30(4.9)$ \\
\hline & $\begin{array}{l}1 \text { (Dyspnoea when } \\
\text { hurrying or walking up a } \\
\text { slight hill) }\end{array}$ & $231(37.8)$ \\
\hline & $\begin{array}{l}2 \text { (Walks slower than } \\
\text { people of the same age } \\
\text { because of dyspnoea or } \\
\text { has to stop for breath } \\
\text { when walking at own } \\
\text { pace) }\end{array}$ & $1818(29.6)$ \\
\hline & $\begin{array}{l}3 \text { (Stops for breath after } \\
\text { walking } 100 \text { yards or after } \\
\text { a few minutes) }\end{array}$ & $118(19.3)$ \\
\hline & $\begin{array}{l}4 \text { (Too dyspnoeic to leave } \\
\text { the house or breathless } \\
\text { when dressing) }\end{array}$ & $51(8.3)$ \\
\hline & Mean (SD) & \\
\hline Age & 70.62 (11.96) & \\
\hline Age at diagnosis & $62.26(11.80)$ & \\
\hline $\begin{array}{l}\text { Duration with } \\
\text { COPD }\end{array}$ & $6.91(6.0)$ & \\
\hline
\end{tabular}

COPD, chronic obstructive pulmonary disease; mMRC, modified Medical Research Council Dyspnoea Scale staging.;

items, weighted kappa ranged from 0.74 (item 24) to 0.90 (item 21).

Concerning precision of the LW-CI-COPD, SEM was $34.94(<0.5 \mathrm{SD}=8.73)$ for the total score of the scale, and for the domains ranged from 1.21 to 1.97 . See table 2 for more details. 
Table 2 Feasibility/acceptability, reliability and precision of the LW-CI-COPD

\begin{tabular}{|c|c|c|c|c|c|c|}
\hline & \multicolumn{6}{|l|}{ LW-CI-COPD } \\
\hline & Acceptance & Coping & Self-management & Integration & Adjustment & Total \\
\hline Full computable data (\%) & 100 & 100 & 100 & 100 & 100 & 100 \\
\hline Floor effect (\%) & 5.1 & 0.3 & 0.2 & 0.3 & 0.7 & 0.2 \\
\hline Ceiling effect (\%) & 16.7 & 5.2 & 11.3 & 17.0 & 15.2 & 0.8 \\
\hline Skewness & -0.40 & -0.43 & -2.64 & -0.43 & -0.16 & -0.19 \\
\hline Cronbach's alpha & 0.90 & 0.83 & 0.77 & 0.79 & 0.89 & 0.92 \\
\hline Interitem correlation & $0.55-0.78$ & $0.26-0.54$ & $0.35-0.53$ & $0.24-0.59$ & $0.40-0.72$ & - \\
\hline Item-total correlation corrected & $0.70-0.84$ & $0.46-0.68$ & $0.51-0.65$ & $0.39-0.67$ & $0.57-0.80$ & - \\
\hline Item homogeneity & 0.68 & 0.41 & 0.47 & 0.43 & 0.57 & - \\
\hline Reproducibility (ICC) & 0.89 & 0.86 & 0.88 & 0.90 & 0.91 & 0.92 \\
\hline Precision (SEM) (0.5 SD) & $1.33(2)$ & $1.97(2.63)$ & $1.21(1.75)$ & $1.22(1.93)$ & $1.63(2.71)$ & $4.94(8.73)$ \\
\hline
\end{tabular}

ICC, intraclass correlation coefficient; LW-Cl-COPD, Living with Chronic Illness Scale for patients with chronic obstructive pulmonary disease; SEM, SE of measurement.

Related to convergent validity, the LW-CI-COPD showed strong relationships with DUFSS $(r=0.64)$, SLS-6 $(r=0.57)$ and domain 2 of WHOQOL-BREF $(r=0.52)$. The LW-CICOPD presented negligible correlation values with age and COPD duration. See table 3 for further information.
Regarding internal validity, domains intercorrelated from 0.03 to 0.71 (table 3 ). In relation to known-groups validity, results showed that the total score was significantly different for gender (higher in women), COPD stages according to MMRC and for PGIS, where patients

Table 3 Convergent validity and internal validity of LW-CI-COPD

\section{LW-CI-COPD}

\begin{tabular}{|c|c|c|c|c|c|c|}
\hline & \multicolumn{6}{|l|}{ LW-CI-COPD } \\
\hline & Acceptance & Coping & $\begin{array}{l}\text { Self- } \\
\text { management }\end{array}$ & Integration & Adjustment & Total score \\
\hline \multicolumn{7}{|l|}{ Convergent validity } \\
\hline Age & 0.06 & -0.03 & -0.07 & -0.01 & -0.06 & -0.03 \\
\hline Age at COPD onset & 0.09 & -0.05 & -0.12 & -0.01 & -0.07 & -0.05 \\
\hline COPD duration & -0.04 & 0 & 0.02 & -0.02 & -0.03 & -0.02 \\
\hline WHOQOL-BREF Physical health & 0.26 & 0.12 & 0.14 & 0.22 & 0.21 & 0.25 \\
\hline WHOQOL-BREF Psychological & 0.28 & 0.38 & 0.35 & 0.46 & 0.48 & 0.52 \\
\hline WHOQOL-BREF Social relationships & 0.14 & 0.36 & 0.33 & 0.39 & 0.42 & 0.44 \\
\hline WHOQOL-BREF Environment & 0.16 & 0.38 & 0.37 & 0.46 & 0.43 & 0.47 \\
\hline DUFSS & 0.15 & 0.64 & 0.47 & 0.61 & 0.55 & 0.64 \\
\hline Satisfaction with Life Scale & 0.28 & 0.46 & 0.38 & 0.52 & 0.51 & 0.57 \\
\hline Satisfaction-physical health & 0.22 & 0.38 & 0.34 & 0.41 & 0.41 & 0.46 \\
\hline Satisfaction-well-being & 0.31 & 0.32 & 0.27 & 0.36 & 0.42 & 0.45 \\
\hline Satisfaction-social relations & 0.26 & 0.39 & 0.28 & 0.46 & 0.44 & 0.48 \\
\hline Satisfaction-leisure & 0.2 & 0.44 & 0.35 & 0.5 & 0.44 & 0.51 \\
\hline Satisfaction-financial situation & 0.21 & 0.48 & 0.33 & 0.57 & 0.43 & 0.52 \\
\hline \multicolumn{7}{|l|}{ Internal validity } \\
\hline Coping & 0.12 & - & - & - & - & - \\
\hline Self-management & 0.03 & 0.64 & - & - & - & - \\
\hline Integration & 0.22 & 0.71 & 0.61 & - & - & - \\
\hline Adjustment & 0.18 & 0.65 & 0.64 & 0.67 & - & - \\
\hline
\end{tabular}

DUFSS, Duke-UNC Functional Social Support Questionnaire; ; LW-Cl-COPD, Living with Chronic Illness Scale for patients with chronic obstructive pulmonary disease; WHOQOL-BREF, WHO Quality of Life Instrument-Brief. 


\begin{tabular}{|c|c|c|}
\hline Categories & $\begin{array}{l}\text { LW-CI-COPD } \\
\text { total }\end{array}$ & $P$ value \\
\hline Gender & & $<0.001^{*}$ \\
\hline Men & $66.17(18.31)$ & \\
\hline Women & $69.94(19.36)$ & \\
\hline mMRC stages & & $<0.001 \dagger$ \\
\hline $\begin{array}{l}0 \text { (Dyspnoea only with } \\
\text { strenuous exercise) }\end{array}$ & $72.63(15.92)$ & \\
\hline $\begin{array}{l}1 \text { (Dyspnoea when hurrying or } \\
\text { walking up a slight hill) }\end{array}$ & $69.62(15.97)$ & \\
\hline $\begin{array}{l}2 \text { (Walks slower than people } \\
\text { of the same age because of } \\
\text { dyspnoea or has to stop for } \\
\text { breath when walking at own } \\
\text { pace) }\end{array}$ & $69.40(18.78)$ & \\
\hline $\begin{array}{l}3 \text { (Stops for breath after } \\
\text { walking } 100 \text { yards or after a few } \\
\text { minutes) }\end{array}$ & $62.76(22.73)$ & \\
\hline $\begin{array}{l}4 \text { (Too dyspnoeic to leave the } \\
\text { house or breathless when } \\
\text { dressing) }\end{array}$ & $63.20(20.62)$ & \\
\hline PGIS-based severity levelsł & & $<0.001 \dagger$ \\
\hline None & 71.43 (16.33) & \\
\hline Mild & $68.47(16.70)$ & \\
\hline Moderate & $71.53(19.22)$ & \\
\hline Severe & $59.72(19.20)$ & \\
\hline
\end{tabular}

Mean (SD).

*Mann-Whitney test.

†Kruskal-Wallis test.

‡PGIS-based severity levels: mild 0-2 points; moderate 3 points; severe 4 or more points.

LW-Cl-COPD, Living with Chronic Illness Scale for patients with chronic obstructive pulmonary disease; mMRC, modified Medical Research Council Dyspnoea Scale staging; PGIS, Patient-Based Global Impression of Severity Scale.;

living with a more severe COPD stage had lower scores in LW-CI-COPD than patients living with a milder stage COPD. See table 4 for further information.

\section{DISCUSSION}

Most of the tested psychometric properties of the LW-CICOPD showed satisfactory results in this population. Feasibility and acceptability of the scale were adequate according to the established criteria. There were no missing data, with $100 \%$ of cases fully computable, probably explained by the close supervision carried out by researchers during data collection. The total scores of floor and ceiling effects and the skewness values were into the range of satisfactory values. These results supported the assumption that the LW-CI-COPD covers the full spectrum of the construct being measured, with a satisfactory distribution of the scores for the COPD population.
Regarding reproducibility, test-retest showed excellent results for the domains and the total score, supporting a good degree of stability in the scale. Moreover, precision was also adequate for the total score indicating that it is a sensitive scale for this population and suitable for assessing changes over time. This is an important issue in patients with COPD, who often suffer exacerbations in symptoms that could affect their daily living. ${ }^{39} 40$ This scale could be recommended in nursing research and practice to assess how patients live with the illness and to design and evaluate the impact of specific multitargeted interventions.

Regarding convergent validity, it is important to underline that very few studies focused on the concept 'living with COPD' were identified in the literature and those were mainly describing patients' experiences and quality of life. ${ }^{41-43}$ Therefore, the LW-CI-COPD was compared with other instruments measuring related constructs, such as quality of life or satisfaction with life. As it was hypothesised in this study, the LW-CI-COPD showed correlations with DUFSS, with SLS-6 and with some of the domains of the WHOQOL-BREF, mainly the psychological domain.

The identified correlation between living with COPD and social support has been previously reported by other authors who found relationships between providing a comprehensive intervention, which includes social support, and a reduction of symptoms together with an improvement of quality of life and daily living in patients with COPD. ${ }^{39} 4244$ These findings were consistent with studies conducted with other chronic conditions which identified strong relationships between the process of living with the illness and social support. ${ }^{11}$

Regarding the correlation between living with COPD and satisfaction and quality of life, results were found in line with previous research. ${ }^{45}$ For instance, it has identified the relationship between satisfaction with life, health self-assessment and the way of coping with the situation. ${ }^{45}$ They identified that patients living with COPD reported low satisfaction with life and that it was inversely related to the emotional situation, like anxiety and stress levels.

These results emphasise the need for a comprehensive approach to achieve a positive living focused on the person and not on the illness, including social aspects in the healthcare system. It is necessary to consider patients from the perspective of their health-related situation and of their community and social situation to provide care from a holistic perspective. ${ }^{142}$ This is valuable information when designing nursing-led interventions to contribute to a positive living in patients with COPD and more research focused on these relationships would be needed.

The internal validity for LW-CI-COPD dimensions was satisfactory in all the domains, except for domain 1acceptance. This finding suggests that, while the other domains could not be necessary, acceptance is the first and essential step to achieve a positive living with the illness. Acceptance is an internal, illness-independent process that allows the patient to understand and assume reality. If patients do not achieve a positive living with 
COPD, this could impact negatively in their quality of life and well-being, therefore, the first step to achieve a positive living should always be acceptance. ${ }^{10}{ }^{12}$ This finding is congruent with previous research conducted with people with $\mathrm{COPD}^{46}$ and other populations, like patients with Parkinson's disease. ${ }^{1121}$

The LW-CI-COPD demonstrated satisfactory knowngroups validity, yielding significantly different scores between patients with different COPD severity levels and gender. In regard to the severity of the illness, results indicated that those more severely ill reported worse degree of living with COPD (negative living) than those in early stages. Previous studies in patients with COPD showed similar results regarding the relationships between illness severity and the quality of life or well-being. ${ }^{47-49}$ This could be explained because if the symptoms worsen, patients could experience more limitations in activities of daily living and poorer sleep quality, which could impact negatively on their quality of life. ${ }^{5}$ Other authors who have studied the correlation between the level of severity of the COPD and quality of life found similar results. ${ }^{49}$ They highlighted that those more severely ill scored worse quality of life in all the measured domains. ${ }^{50}$ Nevertheless, the decrement in the perceived quality of life appeared even in the early stages of the disease.$^{50}$ Therefore, it seems to be essential to design specific interventions for patients with COPD at all the stages of the illness in order to improve their capacity of living with it.

Another finding that supported the satisfactory knowngroups validity of the scale was the fact that women showed better positive living with COPD than men, which could suggest a better acceptance of the situation. There are well-known differences between men and women in diagnosis, pathophysiology and presentation of COPD, and also in response to treatment. ${ }^{51}$ Taking into account these differences, the LW-CI-COPD should be able to discriminate between men and women in regard to the way they live with the disease.

Nevertheless, this finding has not been widely supported by previous studies on quality of life in COPD, partly because results were not stratified by gender. ${ }^{9}$ Therefore, it is necessary to conduct further studies considering the gender perspective to establish whether there are differences in patients' quality of life and in the process of living with a chronic condition.

In addition to this, it is worth to mention that this scale may be used to corroborate the assessment of patients' self-care and self-management. This is essential, especially in this population with COPD, as no adequate instrument to measure those aspects and with sounding psychometric properties is available to date. ${ }^{52}$ Self-care reflects a clear priority in nursing care, particularly in the management of chronic conditions as it enables people to deal with symptoms and to adapt to the physical, psychological and social consequences of their illness. ${ }^{52}$ Therefore, the LW-CI-COPD contributes to fill an important gap identified in the existing instruments for patients with COPD.
Some limitations should be considered in this study. First, the inclusion of two countries (Colombia and Spain) could be a limitation because of the cultural differences. In order to minimise language misunderstandings and identify the language and cultural differences, a pilot study was carried out before this study. Second, the test was completed in the office and the retest in patients' home, a circumstance that could have added a spurious variability. Finally, the lack of some important variables, such as lung function assessed by the forced expiratory volume in $1 \mathrm{~s}$, could be deemed as a limitation. However, these kinds of variables are focused on a specific aspect of COPD, do not always correlate with dyspnoea, health status or exercise capacity and do not reflect the way COPD impairs the patients' daily living. ${ }^{53}$ While the LW-CI-COPD measures the disease in a holistic manner, measures such as the mMRC would be more strongly correlated with it.

This study also has some strengths as the large number of patients who participated in the study $(\mathrm{n}=612)$, considering the potential difficulties in the recruitment of this population due to the symptomatology and disease exacerbations. ${ }^{54}$ The large sample size allowed not having missing data at the end of the study and having a generalisable sample of people living with COPD. Moreover, the sample represented a heterogeneous population showing the different levels of illness severity, according to mMRC (from 0 to 4). Previous studies have underlined the difficulty of recruiting patients at the two extreme levels, as they do not seek medical treatment until they are symptomatic, and those with severely impaired lung function are frequently hospitalised. ${ }^{54}$ In addition to this, the inclusion of Spanish-speaking population from different cities and two countries supported the consistency of the results and the possibility of generalisation at least for this cultural and linguistic setting.

In conclusion, this validation study of the LW-CICOPD showed that it is a feasible, acceptable, reliable, valid and precise instrument to measure the process of living with COPD in the Spanish-speaking population. Future developments include its validation according to Rasch analysis, a method derived from the item response theory that provides further information about the measurement properties of a scale, completing the information provided by the classic test theory; and the analysis of its ability to detect changes due to treatment. The LW-CI-COPD fulfils a gap in research instruments to measure the process of living with this chronic illness. In addition, this scale could be incorporated in nursing daily practice to achieve a comprehensive understanding of the meaning of living with COPD. Moreover, this scale could be useful to identify the determinant factors for a positive living with the disease, helping nurses to prevent negative aspects, like denial or lack of adjustment. This knowledge could reduce visits to emergency departments and hospitalisation, and therefore, the burden for the healthcare system. Thus, we advocate the necessity to incorporate in nursing practice holistic measuring 
scales, as LW-CI-COPD, in addition to disease-specific tools, to be able to provide an integral, individualised and cost-effective healthcare.

The knowledge achieved with this scale could be crucial to design and evaluate individualised interdisciplinary care in relation with social work professionals led by nurses and based on each patient's perspective. These interventions would address all the needs of patients with COPD, including social issues, an aspect highlighted in this research. In other words, the interventions would be focused on providing interdisciplinary, holistic and comprehensive care to patients living with COPD.

\section{Author affiliations}

${ }^{1}$ Faculty of Nursing and Chiropody, University of Valencia, Valencia, Spain ${ }^{2}$ National Centre of Epidemiology and Consortium for Biomedical Research in Neurodegenerative Diseases (Centro de Investigación Biomédica en Red sobre Enfermedades Neurodegenerativas/CIBERNED), Carlos III Institute of Health, Madrid, Spain

${ }^{3}$ Facultad de Enfermería y Rehabilitación, Universidad de La Sabana, Chia, Colombia ${ }^{4}$ La Rioja Health Care System, La Rioja, Spain

${ }^{5}$ Faculty of Legal and Social Science, University of La Rioja, La Rioja, Spain

${ }^{6}$ Department of Cardiology, Hospital Costa del Sol, Marbella, Spain

${ }^{7}$ Faculty of Medicine, Autonomous University of Madrid, Madrid, Spain

${ }^{8}$ School of Health Sciences, NIHR ARC Wessex, University of Southampton, Southampton, UK

Acknowledgements The authors thank the participants living with COPD for taking part in this study, and all of the organisations who helped us to recruit participants. The authors also appreciate the support in the data recruitment process received from the following multidisciplinary researchers: Lorena Lopez (Madrid Healthcare system), Alfonso Meneses (Complutense University of Madrid), Nerea Elizondo (Navarra Healthcare System), Marta Aranda-Gallardo (Costa del Sol Hospital), Maria Eugenia Ursua (Navarra Healthcare System), Jorge Caro (Andalusian Public Health System) and David Perez-Manchon (Camilo Jose Cela University). Besides, the authors would like to thank the Ministry of Science, Innovation and University of the Spanish Government for the economical support provided to carry out this study.

Contributors LA and CRB conceived the study, secured its funding and managed its overall direction, and contributed to the study design. SC, LA, GC, AFR, MIRd0, NC, ET-A and MVNS contributed to the ethics and other approvals for the access to the patients and data collection. SC, LA, GC, AFR, MIRdO, NC, ET-A and MVNS were responsible for jointly participant recruitment including patient and public involvement. LA and CRB were responsible for data management (entry, checking) and data analysis and interpretation. SC and LA drafted the paper, which was critically reviewed by all the authors. All authors contributed to revisions and approved the final version of the manuscript.

Funding This work was supported in Spain by the Ministry of Science, Innovation and University (FEDER/Ministerio de Ciencia, Innovación y Universidades - Agencia Estatal de Investigación) grant number CS02017-82691-R. In Colombia, the study was supported by the Universidad de La Sabana (ENF-28-2019).

Competing interests None declared.

Patient consent for publication Obtained.

Ethics approval In addition to the Ethics Committee of the University of Navarra in Spain (reference number 2017.099), the study was approved by the following ethics committees: Provincial Research of Malaga, Navarra Healthcare System, Madrid Healthcare System, Generalitat of Valencia and La Rioja Healthcare System. The study was also approved by the Ethics Committee of the Universidad de La Sabana in Colombia (reference number 013). Furthermore, the study was conducted following the Declaration of Helsinki and with standard operating procedures that guaranteed compliance with Good Clinical Practice. All participants signed their informed consent after receiving the pertinent information and before inclusion in the study. In addition, all primary and secondary centres involved in the data collection in Spain and Colombia reviewed and approved the study.

Provenance and peer review Not commissioned; externally peer reviewed.
Data availability statement Data are available upon reasonable request to the corresponding author. All data relevant to the study are included in the article. Only members of the research team (ie, corresponding author) have access to the study data. The full anonymised data set was shared between the principal investigator of the study and the research member involved in the data analysis.

Open access This is an open access article distributed in accordance with the Creative Commons Attribution Non Commercial (CC BY-NC 4.0) license, which permits others to distribute, remix, adapt, build upon this work non-commercially, and license their derivative works on different terms, provided the original work is properly cited, appropriate credit is given, any changes made indicated, and the use is non-commercial. See: http://creativecommons.org/licenses/by-nc/4.0/.

ORCID iD

Leire Ambrosio http://orcid.org/0000-0002-9450-7210

\section{REFERENCES}

1 World Health Organization. Health systems respond for noncommunicable diseases: time for ambition, 2019. Available: http:// www.who.int/topics/noncommunicable-diseases

2 Ambrosio L, García-Vivar C. [Horizon 2025 for chronic care]. An Sist Sanit Navar 2020;43:5-7.

3 Dixon $\mathrm{P}$, Hollingworth W, Benger J, et al. Observational costeffectiveness analysis using routine data: admission and discharge care bundles for patients with chronic obstructive pulmonary disease. Pharmacoecon Open 2020 doi:10.1007/s41669-02000207-w

4 Ho T, Cusack RP, Chaudhary N, et al. Under- and over-diagnosis of COPD: a global perspective. Breathe 2019;15:24-35.

5 Smith MC, Wrobel JP. Epidemiology and clinical impact of major comorbidities in patients with COPD. Int J Chron Obstruct Pulmon Dis 2014;9:871-88.

6 World Health Organization. World health statistics 2019: monitoring health for the SDGs, 2019. Available: https://www.who.int/gho/ publications/world_health_statistics/2019/en/

7 Instituto Nacional de Estadística. Estadística de defunciones según causa de muerte, 2019. Available: https://www.ine.es/prensa/edcm 2018.pdf

8 Departamento Administrativo Nacional de Estadística Bogotá. Boletín Técnico Estadísticas Vitales, 2019. Available: https://www. dane.gov.co

9 Blánquez Moreno C, Colungo Francia C, Alvira Balada MC, et al. [Effectiveness of an educational program for respiratory rehabilitation of Chronic Obstructive Pulmonary Disease patients in Primary Care in improving the quality of life, symptoms, and clinical risk]. Aten Primaria 2018;50:539-46.

10 Portillo Vega MC, Senosiain García JM, Arantzamendi Solabarrieta $\mathrm{M}$, et al. ReNACE Project. Patients and relatives living with Parkinson's disease: preliminary results of Phase I. Rev Cient Soc Esp Enferm Neurol 2012;36:31-8.

11 Ambrosio L, Portillo MC, Rodríguez-Blázquez C, et al. Living with chronic illness scale: international validation of a new self-report measure in Parkinson's disease. npj Parkinson's Disease 2016;2:1-6.

12 Ambrosio L, Senosiain García JM, Riverol Fernández M, et al. Living with chronic illness in adults: a concept analysis. J Clin Nurs 2015;24:2357-67.

13 Bestall JC, Paul EA, Garrod R, et al. Usefulness of the Medical Research Council (MRC) dyspnoea scale as a measure of disability in patients with chronic obstructive pulmonary disease. Thorax 1999;54:581-6.

14 DePew ZS, Garofoli AC, Novotny PJ, et al. Screening for severe physical inactivity in chronic obstructive pulmonary disease: the value of simple measures and the validation of two physical activity questionnaires. Chron Respir Dis 2013;10:19-27.

15 World Health Organization. The World Health Organization Quality of Life (WHOQOL)-BREF, 2004. Available: http://www.who.int/ substance_abuse/research_tools/en/english_whogol.pdf

16 Jones PW, Quirk FH, Baveystock CM, et al. A self-complete measure of health status for chronic airflow limitation. Am Rev Respir Dis 1992;145:1321-7.

17 Jones PW, Harding G, Berry P, et al. Development and first validation of the COPD assessment test. Eur Respir J 2009;34:648-54.

18 Ferrer M, Alonso J, Prieto L, et al. Validity and reliability of the St George's respiratory questionnaire after adaptation to a different language and culture: the Spanish example. Eur Respir J 1996;9:1160-6.

19 Gallefoss F, Bakke PS, Rsgaard PK. Quality of life assessment after patient education in a randomized controlled study on asthma and 
chronic obstructive pulmonary disease. Am J Respir Crit Care Med 1999:159:812-7.

20 Osman IM, Godden DJ, Friend JA, et al. Quality of life and hospital re-admission in patients with chronic obstructive pulmonary disease. Thorax 1997; 52:67-71

21 Ambrosio L, Navarta-Sánchez MV, Meneses A, et al. [Living with Chronic Illness Scale: Pilot study in patients with several chronic diseases]. Aten Primaria 2020;52:142-50.

22 von Elm E, Altman DG, Egger M, et al. The strengthening the reporting of observational studies in epidemiology (STROBE) statement: guidelines for reporting observational studies, 2020.

23 Bowling A. Research methods in health: investigating health and health services. 4th edn. McGraw-Hill, 2014.

24 Peduzzi P, Concato J, Kemper E, et al. A simulation study of the number of events per variable in logistic regression analysis. $J$ Clin Epidemiol 1996;49:1373-9.

25 Stebbing GT. Clinical rating scale development. In: Sampaio CG, ed. Rating scales in Parkinson's disease. Clinical practice and research. Oxford: University Press;, 2012: 3-9.

26 Ayala A, Rodríguez-Blázquez C, Frades-Payo B, et al. Propiedades psicométricas del Cuestionario de Apoyo social Funcional Y de la Escala de Soledad en adultos mayores no institucionalizados en España. Gac Sanit 2012;26:317-24.

27 Broadhead WE, Gehlbach SH, de Gruy FV, et al. The Duke-UNC functional social support questionnaire. Measurement of social support in family medicine patients. Med Care 1988;26:709-7.

28 Mazaheri M, Theuns P. A study of how satisfaction and dissatisfaction with life overall relate to satisfaction and dissatisfaction in specific life domains. Patient Reported Outcomes Newsletter 2006;37:24-7.

29 Martínez-Martín P, Rodríguez-Blázquez C, Alvarez M, et al. Parkinson's disease severity levels and MDS-Unified Parkinson's disease rating scale. Parkinsonism Relat Disord 2015;21:50-4.

30 Smith S, Lamping D, Banerjee S, et al. Measurement of healthrelated quality of life for people with dementia: development of a new instrument (DEMQOL) and an evaluation of current methodology. Health Technol Assess 2005;9:1-93.

31 van der Linden FAH, Kragt JJ, Klein M, et al. Psychometric evaluation of the multiple sclerosis impact scale (MSIS-29) for proxy use. $J$ Neurol Neurosurg Psychiatry 2005;76:1677-81.

32 Aaronson N, Alonso J, Burnam A, et al. Assessing health status and quality-of-life instruments: attributes and review criteria. Qual Life Res 2002;11:193-205.

33 Landis JR, Koch GG. The measurement of observer agreement for categorical data. Biometrics 1977;33:159-74.

34 Cicchetti DV. Guidelines, criteria, and rules of thumb for evaluating normed and standardized assessment instruments in psychology. Psychol Assess 1994;6:284-90.

35 Clark LA, Watson D. Constructing validity: basic issues in objective scale development. Psychol Assess 1995;7:309-19.

36 Mokkink LB, Terwee CB, Patrick DL, et al. The COSMIN checklist for assessing the methodological quality of studies on measurement properties of health status measurement instruments: an international Delphi study. Qual Life Res 2010:19:539-49.

37 Juniper EF, Guyatt GH, Jaeschke R. How to develop and validate a new health-related quality of life instrument. In: Spilker B, ed. Quality of life and pharmacoeconomics in clinical trials. Philadelphia: Lippincott-Raven Publishers, 1996: 49-56.
38 Luo N, Johnson JA, Shaw JW, et al. Self-reported health status of the general adult U.S. population as assessed by the EQ-5D and health Utilities index. Med Care 2005;43:1078-86.

39 Lenferink A, Brusse-Keizer M, van der Valk PD, et al. Selfmanagement interventions including action plans for exacerbations versus usual care in patients with chronic obstructive pulmonary disease. Cochrane Database Syst Rev 2017;8:CD011682.

40 Wang LH, Zhao Y, Chen LY, et al. The effect of a nurse-led selfmanagement program on outcomes of patients with chronic obstructive pulmonary disease. Clin Respir J 2020;14:148-57.

41 Barken TL, Thygesen E, Söderhamn U. Unlocking the limitations: living with chronic obstructive pulmonary disease and receiving care through telemedicine-A phenomenological study. J Clin Nurs 2018;27:132-42.

42 Costa X, Gómez-Batiste X, Pla M, et al. Vivir Con La enfermedad pulmonar obstructiva crónica avanzada: El impacto de la disnea en Los pacientes Y cuidadores. Atención Primaria 2016;48:665-73.

43 Valencia-Rico CL, Burbano-López C. Living with chronic obstructive pulmonary disease: a story conditioned by the symptoms. Enferm Clin 2020;30:309-16.

44 McCarthy B, Casey D, Devane D, et al. Pulmonary rehabilitation for chronic obstructive pulmonary disease. Cochrane Database Syst Rev 2015;23:CD003793.

45 Drop B, Janiszewska M, Barańska A, et al. Satisfaction with life and adaptive reactions in people treated for chronic obstructive pulmonary disease. Adv Exp Med Biol 2018;1114:41-7.

46 Milner Siobhan CM, Bourbeau J, Ahmed S, et al. Improving acceptance and uptake of pulmonary rehabilitation after acute exacerbation of COPD: Acceptability, feasibility, and safety of a PR "taster" session delivered before hospital discharge. Chron Respir Dis 2019;16:1-12.

47 Medinas Amorós M, Mas-Tous C, Renom-Sotorra F, et al. Healthrelated quality of life is associated with COPD severity: a comparison between the gold staging and the bode index. Chron Respir Dis 2009;6:75-80.

48 Collado-Mateo D, Adsuar JC, Olivares PR, et al. [Health-related quality of life in Chilean patients with chronic obstructive pulmonary disease]. Rev Med Chil 2017;145:147-55.

49 Fernandez-Vargas AM, Bujalance Zafra MJ, Leiva Fernández F, et al. Correlation Between Subjective and Objective Health Measurements in Patients With Chronic Obstructive Pulmonary Disease (COPD)] Aten prim 2001;28:579-87.

50 Nonato NL, Díaz O, Nascimento OA, et al. Comportamiento de la calidad de vida (SGRQ) en pacientes Con EPOC según LAS puntuaciones bode. Archivos de Bronconeumología 2015;51:315-21.

51 Robles PG, Brooks D, Goldstein R, et al. Gender-associated differences in pulmonary rehabilitation outcomes in people with chronic obstructive pulmonary disease: a systematic review. $J$ Cardiopulm Rehabil Prev 2014;34:87-97.

52 Clari M, Matarese M, Alvaro R, et al. Measurement properties of instruments evaluating self-care and related concepts in people with chronic obstructive pulmonary disease: a systematic review. Heart Lung 2016;45:441-8.

53 Glaab T, Vogelmeier C, Buhl R. Outcome measures in chronic obstructive pulmonary disease (COPD): strengths and limitations. Respir Res 2010;11:79.

54 Jones PW, Brusselle G, Dal Negro RW, et al. Health-related quality of life in patients by COPD severity within primary care in Europe. Respir Med 2011;105:57-66. 